\title{
Long-term results of Freestyle stentless bioprosthesis in the aortic position: A single-center prospective cohort of 500 patients
}

\author{
Nicolas Amabile, MD, PhD, ${ }^{\mathrm{a}}$ Olivier M. Bical, MD, ${ }^{\mathrm{b}}$ Alexandre Azmoun, MD, ${ }^{\mathrm{b}}$ Ramzi Ramadan, MD, \\ Remi Nottin, MD, ${ }^{\mathrm{b}}$ and Philippe H. Deleuze, $\mathrm{MD}^{\mathrm{b}}$
}

Objective: Stentless xenograft bioprostheses may be the future valve of choice for aortic valve replacement. The study aim was to investigate the long-term clinical outcome after aortic valve replacement with the Medtronic Freestyle bioprosthesis (Medtronic Inc, Minneapolis, Minn).

Methods: Between April 1997 and November 2004, a total of 500 patients (mean age, $74.5 \pm 9.6$ years; $52 \%$ were male) underwent aortic valve replacement with a Freestyle bioprosthesis, without population selection. The surgical procedure used a modified subcoronary technique in 479 patients and a complete root replacement in 21 patients, conducted with mini-extracorporeal circulation. Concomitant procedures included coronary artery bypass grafting in 122 patients (24\%) and mitral valve repair/replacement in 11 patients.

Results: The mean cardiopulmonary bypass time was $98 \pm 26$ minutes, and total aortic crossclamp time was 77 \pm 19 minutes. Operative mortality was $5.2 \%$. The median follow-up time was $104.8 \pm 5.7$ months. During this period, there were 224 deaths $(\mathrm{n}=122$ cardiovascular and $\mathrm{n}=102$ noncardiovascular deaths). The actuarial survivals from cardiovascular and valve-related mortality were $67 \% \pm 3 \%$ and $70 \% \pm 4 \%$, respectively, at 10 years. Freedom from structural valve deterioration at 10 years was $94 \% \pm 2 \%$. The linearized structural valve deterioration incidence was $0.6 \%$ per patient/year. Multivariate Cox regression analysis revealed that older age, impaired renal function, and coronary artery disease were independent predictors of cardiovascular death. In the subgroup of patients aged less than 65 years at implantation $(n=45)$, the actuarial cardiovascular survival was $83 \% \pm 8 \%$ and freedom from structural valve deterioration was $89 \% \pm 6 \%$ at 10 years.

Conclusions: The use of the Freestyle bioprosthesis for aortic valve replacement resulted in good long-term cardiovascular survival and freedom from structural valve deterioration in this cohort regardless of age at implantation. (J Thorac Cardiovasc Surg 2014;148:1903-11)

See related commentary on pages 1911-2.

The use of bioprostheses for aortic valve replacement (AVR) is recommended by international guidelines in patients aged more than 65 years, because of the decreased risk of device structural deterioration and the absence of required anticoagulation in this population with high risk for bleeding. ${ }^{1}$ Bioprostheses can be broadly divided into 2 categories according to the presence or absence of a metallic stent supporting the biological tissue leaflet. The choice of a stented or stentless device for AVR remains debated, because they are purported to confer advantages over their counterparts.

From the Cardiology Department ${ }^{\mathrm{a}}$ and Cardiac Surgery Department, ${ }^{\mathrm{b}}$ Centre Chirurgical Marie Lannelongue, Le Plessis-Robinson, France.

Disclosures: Dr Amabile reports consulting fees from St. Jude Medical and Boston Scientific and lecture fees from St. Jude Medical and The Medicines Company. All other authors have nothing to disclose with regard to commercial support.

Received for publication Sept 10, 2013; revisions received Jan 6, 2014; accepted for publication Feb 20, 2014; available ahead of print March 28, 2014.

Address for reprints: Philippe H. Deleuze, MD, Department of Adult Cardiac Surgery, Centre Marie Lannelongue, 133 Ave de la Resistance, 92350 Le Plessis Robinson, France (E-mail: p.deleuze@ccml.fr).

$0022-5223 / \$ 36.00$

Copyright (c) 2014 by The American Association for Thoracic Surgery

http://dx.doi.org/10.1016/j.jtcvs.2014.02.063
The Freestyle stentless (Medtronic Inc, Minneapolis, Minn) aortic bioprosthesis is a xenograft composed of a thin synthetic sewing cuff attached to a glutaraldehydepreserved porcine aortic root using an alpha-amino oleic acid leaflet anti-calcification treatment. The absence of stent has been reported to provide better hemodynamic properties compared with stented biological valves, with less turbulent flow and larger efficient effective orifice area. $^{2}$ These characteristics could lead to lower transvalvular gradient and better valve duration. ${ }^{2}$ Thus, the use of stentless bioprostheses (SLBs) might improve survival, reduce the structural deterioration risk, and minimize deleterious long-term impact on left ventricle function. Recent results from randomized trials and meta-analysis suggest a superiority of stentless over stented biological standard bioprostheses, ${ }^{3,4}$ especially in patients with left ventricle dysfunction and a small aortic annulus. ${ }^{2}$

Despite the introduction of SLBs in the early 1990s, longterm outcome data are still required to assess their durability and safety. ${ }^{1}$ Our group previously reported excellent shortand mid-term survivals in patients of a wide age range. ${ }^{5}$ The purpose of the present study was to describe the clinical outcome in a large cohort of all-comer patients who received a Freestyle bioprosthesis implantation and were prospectively followed up for as long as 12 years. 

Abbreviations and Acronyms
AVR $=$ aortic valve replacement
$\mathrm{CSB}=$ conventional stented bioprosthesis
$\mathrm{LVEF}=$ left ventricular ejection fraction
SLB $=$ stentless bioprosthesis
SVD $=$ structural valve deterioration
TAVI $=$ transaortic valve implantation
$\mathrm{VKA}=$ vitamin $\mathrm{K}$ antagonist

\section{MATERIAL AND METHODS \\ Patient Population}

This prospective observational cohort study included patients who benefited from Freestyle bioprostheses implantation by 2 surgeons (O.M.B. and P.H.D.) working together in 2 institutions between April 1997 and November 2004. ${ }^{5}$ To provide realistic clinical results, the Freestyle bioprosthesis was used immediately after a choice of biological prosthetic valves had been made, with no selection on age, left ventricular function, or operative risk. There was no specific inclusion or exclusion criterion for Freestyle implantation in this all-comers cohort. Our local ethics committee approved the study, and informed signed consent was obtained.

\section{Operative Technique}

Cardiopulmonary bypass was conducted with a mini-extracorporeal circulation circuit (Jostra MECC System; Jostra AG, Hirrlingen, France), systemic normothermia, and warm antegrade discontinued blood cardioplegia. The Freestyle bioprosthesis was implanted using the modified subcoronary technique ${ }^{6}$ or the complete aortic root replacement with coronary artery reimplantation. ${ }^{7}$ Our first option was the subcoronary technique ("cylinder in a cylinder") to optimize the procedure of AVR by shortening the cardiopulmonary bypass and aortic crossclamp times. The full root replacement technique was performed in case of aortic root dilation.

In all techniques, a transverse aortotomy was used. In the subcoronary technique, the inflow of the porcine root was secured with simple interrupted sutures. The porcine valve was trimmed by excision of the remnants of the aortic tissue above the orifices for the coronary sinuses, leaving the noncoronary sinus wall intact. In case of a small aortic annulus and low right coronary ostium, the Freestyle device was rotated to avoid the potential obstruction created by the folded fabric cloth covering the muscle bar of the prosthesis. ${ }^{6}$ In the total root replacement, the aorta was transected above the sinotubular ridge. Both coronary ostia were mobilized with buttons of aortic wall. The remaining tissue of the sinus of Valsalva was excised. A quadrangular portion of the porcine aortic sinus was excised to remove the porcine coronary artery for both the left and right coronary arteries. The porcine valve was rotated to allow optimal right coronary artery implantation in the Freestyle noncoronary wall. The coronary buttons were sewn to the corresponding sinus of Valsalva with a continuous suture, and the outflow portion of the graft was sutured to the crest of the native aorta.

During the same period, the Freestyle bioprosthesis could not be implanted in a subcoronary fashion in 30 patients because of technical contraindications. These included heavy calcification of the native aortic wall itself and calcifications localized beneath the coronary ostia, both of which compromised the upper suture of the stentless valve. Problems were also encountered in redo aortic operations when the aortotomy could not always be performed at the appropriate location.

\section{Clinical and Echocardiography Data}

Preoperative clinical and surgical data were recorded prospectively for each patient. Preoperative and postoperative echocardiographic data were obtained according to the international guidelines and included left ventricle ejection fraction, mean transvalvular gradient measurement, and effective orifice area calculation. ${ }^{8}$ The following variables were considered as potential outcome determinants: age, gender, body mass index, body surface area, diabetes, preoperative renal function (estimated by the Modification of Diet in Renal Disease calculation of the creatinine clearance), concomitant procedure, operative technique, re-replacement of the aortic valve, physiologic subgroup as aortic stenosis, aortic insufficiency or combined aortic valve disease, history of endocarditis, previous cardiac surgery, valve size, baseline pre-intervention transaortic gradient, left ventricular ejection fraction (LVEF), and preoperative pulmonary hypertension.

\section{Anticoagulation Regimen}

Our policy regarding anticoagulation followed the European Society of Cardiology guidelines. ${ }^{9}$ Oral anticoagulation with vitamin $\mathrm{K}$ antagonists (VKAs) was provided to patients with chronic and recurrent atrial fibrillation. Although the decision to give or not give VKAs to elderly patients was left to the discretion of the cardiologist, the general consensus in France at this time was to switch from VKA to aspirin in subjects aged more than 85 years. Other subjects with previous coronary artery disease or at high cardiovascular risk received aspirin therapy $(75 \mathrm{mg} / \mathrm{d})$ after surgery.

\section{Follow-up Data Analysis}

Outcomes were analyzed according to the guidelines of the American Association for Thoracic Surgery for reporting morbidity and mortality after cardiac valvular operations. ${ }^{10}$ Follow-up information was obtained by a single investigator between April 1997 and July 2010, using a standardized interview or telephone questionnaire. Data regarding all-cause, cardiac, and valve-related mortalities, structural valvular deterioration, operated valvular endocarditis, bleeding events, and thromboembolic events were collected and integrated into our database.

\section{Statistical Analysis}

Statistical analysis was performed with SPSS 21.0 (SPSS Inc, Chicago, Ill) and SAS 9.33 (SAS Institute Inc, Cary, NC). Data are expressed as mean and standard deviation.

Patient survivals from all-cause, cardiovascular, and valve-related mortalities, and structural valve deterioration (SVD) were analyzed, and Kaplan-Meier actuarial survival curves were constructed. In addition, we performed cumulative actual incidence analysis of SVD to provide a mortality-adjusted event-free percentage. ${ }^{11}$ Differences between survival curves were evaluated using the log-rank test.

We used a multivariate Cox model with stepwise regression to assess the relation of covariates with the incidence of the different clinical end points during follow-up. Univariate Cox proportional hazards regression analyses were first performed among established predictors of long-term cardiovascular mortality. All covariates with a $P$ value less than .1 were then included in the multivariate regression model to identify independent predictors of the primary end point. The validity of the proportionality assumption was verified for all covariates by the likelihood ratio test. A 2-sided alpha level of 0.05 was considered the threshold for statistical significance.

\section{RESULTS \\ Baseline Characteristics}

Between April 1997 and November 2004, a total of 850 patients underwent AVR by the 2 selected surgeons. Among them, 500 patients (age range, 26-91 years) underwent AVR with implantation of a Freestyle bioprosthesis, 30 patients underwent AVR with implantation of another bioprosthesis because of Freestyle implantation impossibility, and 320 
TABLE 1. Baseline clinical and echography characteristics of the study population

\begin{tabular}{lc}
\hline \multicolumn{1}{c}{ Parameter } & $\mathbf{N}=\mathbf{5 0 0}$ \\
\hline Age (y) & $74.5 \pm 9.6$ \\
Male gender, n (\%) & $259(52)$ \\
Significant coronary artery disease, $\mathrm{n}(\%)$ & $178(35)$ \\
Diabetes mellitus, $\mathrm{n}(\%)$ & $110(22)$ \\
Peripheral artery disease, $\mathrm{n}(\%)$ & $60(12)$ \\
Creatinine clearance $\leq 60 \mathrm{~mL} / \mathrm{min} / \mathrm{m}^{2}, \mathrm{n}(\%)$ & $135(27)$ \\
Body mass index $\left(\mathrm{kg} / \mathrm{m}^{2}\right)$ & $26.7 \pm 13.6$ \\
Body surface area $\left(\mathrm{m}^{2}\right)$ & $1.78 \pm 0.23$ \\
Previous cardiac surgery, $\mathrm{n}(\%)$ & $10(2)$ \\
Previous AVR, $\mathrm{n}(\%)$ & $4(1)$ \\
Indications for AVR, $\mathrm{n}(\%)$ & \\
Aortic stenosis with underlying tricuspid valve, $\mathrm{n}(\%)$ & $426(85)$ \\
Aortic stenosis with underlying bicuspid valve, $\mathrm{n}(\%)$ & $13(3)$ \\
Isolated aortic regurgitation, $\mathrm{n}(\%)$ & $37(7)$ \\
Combined aortic valve disease, $\mathrm{n}(\%)$ & $14(3)$ \\
Active endocarditis without aortic regurgitation, $\mathrm{n}(\%)$ & $3(0.5)$ \\
Active endocarditis with aortic regurgitation, $\mathrm{n}(\%)$ & $7(1.5)$ \\
Aortic dissection, $\mathrm{n}(\%)$ & 0 \\
NYHA class, $\mathrm{n}(\%)$ & \\
I/II & $295(59)$ \\
III/IV & $205(41)$ \\
Left ventricle ejection fraction $(\%)$ & $58.6 \pm 0.8$ \\
Preoperative pulmonary hypertension, $\mathrm{n}(\%)$ & $100(20)$ \\
Mean preoperative transaortic gradient (mm Hg) & $52.0 \pm 15.6$ \\
\hline AVR, Aortic valve replacement; $N Y H A$, New York Heart Association. & \\
&
\end{tabular}

patients underwent AVR with implantation of a mechanical prosthesis. Patients implanted after this period with a Freestyle device $(n=600)$ were not included in the study because it was focused on long-term outcome. The baseline characteristics of the population are shown in Table 1.

\section{Operative Data}

The modified subcoronary implantation technique was used in 479 patients $(96 \%)$. The mean cardiopulmonary bypass time was $98 \pm 26$ minutes $(88 \pm 15$ minutes for AVR alone), and the mean aortic crossclamp time was 77 \pm 19 minutes (70 \pm 13 minutes for AVR alone) (Table 2). Both mean cardiopulmonary bypass time and aortic crossclamp times were significantly longer in the patients with complete root replacement versus modified subcoronary implantation ( $128 \pm 34$ minutes vs $97 \pm 25$ minutes, respectively, and $99 \pm 25$ minutes vs $76 \pm 19$ minutes, respectively, $P<.001$ for both). A concomitant procedure was performed in $31 \%$ of the cases. The remaining patients with coronary disease $(10 \%)$ did not undergo coronary artery bypass grafting because the target lesions were distal or secondary. The mean Freestyle bioprosthesis diameter was $22.2 \pm 2.2 \mathrm{~mm}$. A total of $242(48 \%)$ small-diameter bioprostheses (19 or $21 \mathrm{~mm}$ ) were used, mostly in the older female group.
TABLE 2. Operative and postoperative characteristics

\begin{tabular}{lc}
\hline \multicolumn{1}{c}{ Parameter } & $\mathbf{N}=\mathbf{5 0 0}$ \\
\hline Cardiopulmonary bypass time (min) & $98.5 \pm 26.0$ \\
Total aortic crossclamp time (min) & $77.3 \pm 19.3$ \\
Prosthesis diameter (mm) & $22.2 \pm 2.2$ \\
Valve size, $\mathrm{n}(\%)$ & \\
$19 \mathrm{~mm}$ & $82(16)$ \\
$21 \mathrm{~mm}$ & $160(32)$ \\
$23 \mathrm{~mm}$ & $159(32)$ \\
$25 \mathrm{~mm}$ & $78(15.5)$ \\
$27 \mathrm{~mm}$ & $19(4)$ \\
$29 \mathrm{~mm}$ & $2(0.5)$ \\
Freestyle implantation technique & \\
Modified subcoronary technique, $\mathrm{n}(\%)$ & $479(96)$ \\
Complete root replacement, $\mathrm{n}(\%)$ & $21(4)$ \\
Associated procedure, $\mathrm{n}(\%)$ & $157(31)$ \\
Coronary artery bypass graft, $\mathrm{n}(\%)$ & $122(24)$ \\
Mitral valve replacement, $\mathrm{n}(\%)$ & $3(1)$ \\
Mitral valvuloplasty, $\mathrm{n}(\%)$ & $8(2)$ \\
Ascending aortic tube-graft, $\mathrm{n}(\%)$ & $9(2)$ \\
Other, $\mathrm{n}(\%)$ & $15(3)$ \\
Anticoagulation regimen at discharge & \\
None, $\mathrm{n}(\%)$ & $215(43)$ \\
VKA, $\mathrm{n}(\%)$ & $102(20)$ \\
Aspirin, $\mathrm{n}(\%)$ & $285(57)$ \\
\hline VKA, Vitamin K antagonist. &
\end{tabular}

\section{Operative Mortality and Early Outcome}

Twenty-six $(5.2 \%)$ perioperative deaths occurred during the initial hospitalization or within 30 days after surgery. No death occurred in the younger age group ( $<65$ years). Five of 120 patients aged more than 80 years died $(4 \%)$.

\section{Long-Term Outcome}

Follow-up was achieved in 488 patients (median followup, $104.8 \pm 5.7$ months; range, 1-155 months; 2971 patientyears). During this period, there was a total of 224 all-cause deaths, including 122 cardiovascular and 109 valve-related deaths $(\mathrm{n}=11$ deaths caused by structural and nonstructural dysfunction, $\mathrm{n}=8$ fatal embolic events, $\mathrm{n}=14$ fatal hemorrhagic events, $\mathrm{n}=4$ fatal endocarditis, $\mathrm{n}=19$ sudden death, and $\mathrm{n}=53$ unexplained death). Figure 1, $A$ shows the Kaplan-Meier curves for long-term survival among the whole cohort. The actuarial survivals for all-cause, cardiovascular, and valve-related mortality were $44 \% \pm 3 \%$, $67 \% \pm 3 \%$, and $70 \% \pm 4 \%$ at 10 years, respectively, and $31 \% \pm 5 \%, 50 \% \pm 7 \%$, and $58 \% \pm 7 \%$ at 12 years, respectively.

Evidence of SVD was identified in 18 patients and led to reintervention in 10 subjects. The actuarial freedom from SVD was $94 \% \pm 2 \%$ (Figure $1, B$ ), and the actual cumulative incidence of SVD (Figure 1,C) was $3.7 \%$ at 10 years. The poorer actuarial rates reflected the burden of competing 

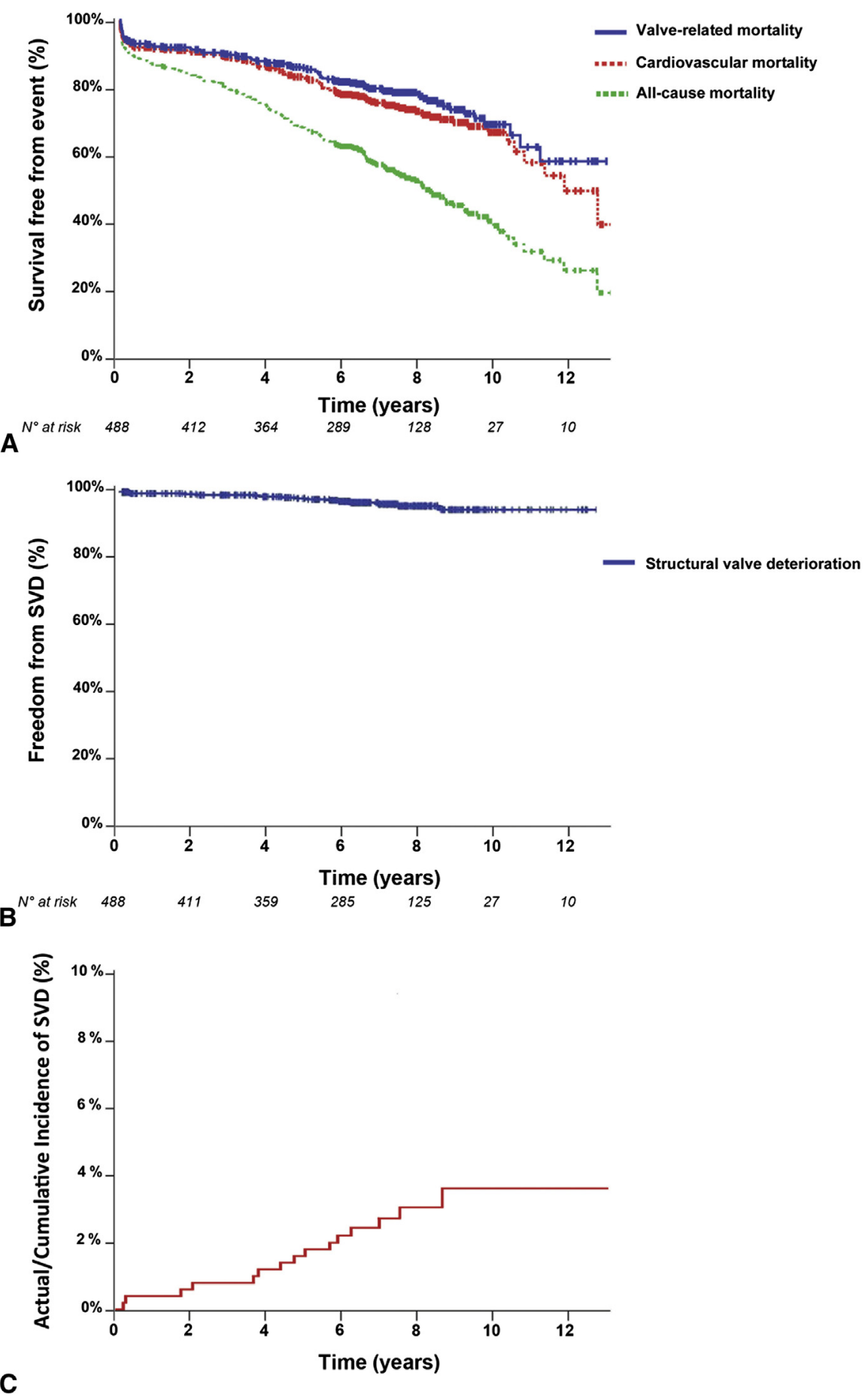

FIGURE 1. Kaplan-Meier actuarial survival curves for all-cause, cardiovascular, valve-related mortality (A), and SVD (B) in the global cohort ( $\mathrm{n}=488$ ). Cumulative incidence of SVD (C). SVD, Structural valve deterioration.

events (death from non-SVD-related causes) that censored the occurrence of SVD.

The pathologic assessment of the explanted bioprosthesis indicated that the mechanism responsible for valve failure was the association of leaflet calcification and tear in
$60 \%$ of patients, leaflet tear in $20 \%$ of patients, and predominant calcification of leaflet and commissures in the remaining $20 \%$ of patients. The linearized annual incidence of SVD was $0.6 \%$ per patient/year. In addition, reoperation was required in 10 cases that were not related to SVD. 
Fourteen patients had bioprosthesis valve endocarditis (linearized annual incidence: $0.5 \%$ per patient/year; actuarial freedom from endocarditis: $96 \% \pm 1 \%$, at 10 years), leading to death in 4 cases. There was no case of valve thrombosis observed during follow-up. A total of 25 patients presented peripheral thromboembolism (mean age, $77 \pm 14.7$ years; $53 \%$ male gender/linearized annual incidence: $0.8 \%$ per patient/year; actuarial freedom from peripheral embolic event $90 \% \pm 3 \%$ at 10 years), including stroke in 17 , transient ischemic attack in 5 , mesenteric ischemia in 1, and acute central retinal artery occlusion in 2. The embolic event was fatal in $32 \%$ of the cases and led to persistent neurologic disabilities in $28 \%$ of the patients. Patients were receiving oral anticoagulation before their embolic event in $36 \%$ of the cases, and $40 \%$ of the patients had evidence of atrial fibrillation or a history of recurrent AF before the embolic event. Finally, $19.6 \%$ of the patients were receiving anticoagulants during follow-up (mostly for atrial fibrillation treatment). Hemorrhages occurred in 28 patients (linearized annual incidence, $0.9 \%$ per patient/year; actuarial freedom from hemorrhagic event, $88 \% \pm 3 \%$, at 10 years), leading to death in 14 .

\section{Long-Term Outcome in Selected Subgroups}

The Freestyle bioprosthesis showed excellent performance and durability in the younger patients of the cohort (age $<65$ years at implantation, $n=45$ ). The 10 -year actuarial survivals from all-cause, cardiovascular, and valverelated mortality were $69 \% \pm 9 \%, 83 \% \pm 7 \%$, and $87 \% \pm 6 \%$, respectively (Figure 2, $A$ ). SVD was observed in 4 patients and led to reintervention in all of them (actuarial freedom from SVD $89 \% \pm 6 \%$ and actual cumulative incidence of SVD $9 \%$ at 10 years) (Figure 2, $B$ and $C$ ).

Moreover, we analyzed outcome in patients aged 80 years or more at implantation $(\mathrm{n}=120)$ and observed that the 10-year actuarial survival from cardiovascular and valve-related mortality were $41 \% \pm 9 \%$ and $50 \% \pm 10 \%$, respectively.

We observed no difference in outcome in patients who received a bioprosthesis with a diameter of $21 \mathrm{~mm}$ or less $(\mathrm{n}=234)$ compared with the other patients (prosthesis diameter $>21 \mathrm{~mm}$ ), as demonstrated by the 10 -year actuarial survival freedom from cardiovascular death $(66 \% \pm$ $6 \%$ vs $68 \% \pm 4 \%$, respectively, $P=.93$ ), valve-related mortality $(66 \% \pm 6 \%$ vs $72 \% \pm 4 \%$, respectively, $P=.62)$, and SVD $(95 \% \pm 2 \%$ vs $94 \% \pm 3 \%$, respectively, $P=.95$ ). Finally, we did not observe any significant impact of impaired LVEF on outcome. Although there was a trend toward a higher cardiovascular mortality (10-year actuarial survival from cardiovascular death: $62 \% \pm 7 \%$ vs $71 \% \pm 4 \%$, respectively, $P=.13$ ), the patients with a baseline LVEF of $50 \%$ or less $(\mathrm{n}=111)$ showed comparable 10 -year survivals from valve-related mortality $(68 \% \pm$ $8 \%$ vs $72 \% \pm 4 \%$, respectively, $P=.52)$ and SVD $(98 \% \pm$
$2 \%$ vs $94 \% \pm 2 \%$, respectively, $P=.46$ ) as the patients with baseline LVEF greater than $50 \%$.

\section{Predictors of Long-Term Outcome After Freestyle Implantation}

Table 3 shows the predictors of cardiovascular death in univariable and multivariable analyses. Cox regression analysis revealed that age at implantation, presence of coronary artery disease, and preoperative creatinine clearance less than $60 \mathrm{~mL} / \mathrm{min} / \mathrm{m}^{2}$ were independent predictors of cardiovascular mortality after adjustment for confounding factors.

Furthermore, we also analyzed predictors of valverelated mortality in these patients (Table 4). We observed that age at implantation and diabetes mellitus independently predicted valve-related mortality. There was no significant effect of other patients' clinical characteristics, operative technique, concomitant procedure, or device size on the outcome in the whole cohort.

\section{DISCUSSION}

The expanding use of valvular bioprostheses among a wide range of patients (including younger patients) highlights the need for durable, efficient, and safe devices. The Freestyle bioprosthesis is a xenograft composed of a thin synthetic sewing cuff attached to a preserved porcine aortic root. The stent-free design allows an excellent conformability of the valve with the native aortic root, leading to increased larger effective orifice area $^{12}$ and less turbulent flow ${ }^{13}$ compared with conventional stented bioprostheses (CSBs). SLBs have a better hemodynamic profile and demonstrate lower transvalvular gradient than CSBs. ${ }^{4,14}$ Moreover, the absence of struts could theoretically impede the degeneration process affecting all bioprostheses, because this phenomenon usually starts on the attachment zones between the leaflets and the struts in CSB, and thus leads to longer durability. ${ }^{15,16}$ Finally, the anticalcification treatment of the bioprosthesis might improve its potential longevity. Of note, recent results showed a $97.9 \% \pm 0.6 \%$ freedom of SVD at 10 years for patients who received the Medtronic Mosaic bioprosthesis (a third-generation alpha-amino oleic acid-treated porcine valve mounted on a stent). ${ }^{17}$ Because the Mosaic and Freestyle bioprostheses differ only by the presence of the stent and show comparable long-term durability, these data might suggest that the demineralization process applied to these devices could largely account for their excellent longterm durability.

Despite these potential benefits, the use of SLB is highly variable among institutions worldwide. ${ }^{18-20}$ These paradoxical results might be explained by the concerns raised regarding SLB real advantages over their counterparts. ${ }^{1,21}$ Major criticisms relate to the increased complexity and higher surgical risk for SLB implantation, 

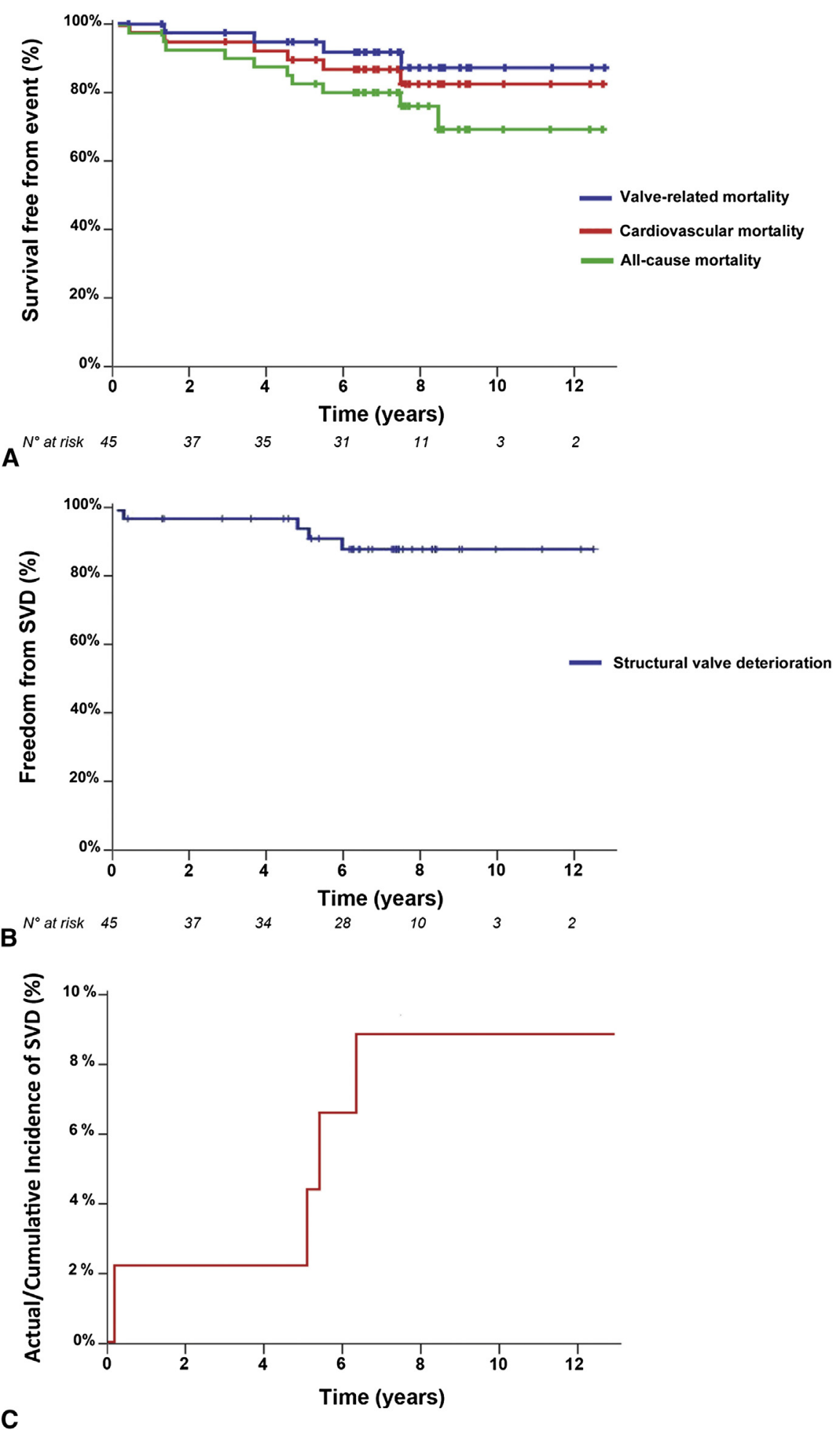

FIGURE 2. Kaplan-Meier actuarial survival curves for all-cause, cardiovascular, valve-related mortality (A), and SVD (B) in patients aged less than 65 years $(\mathrm{n}=45)$. Cumulative incidence of SVD $(C) . S V D$, Structural valve deterioration.

as well as the limited and conflicting results regarding the durability of these bioprostheses and long-term outcome. ${ }^{1,2}$ Different authors have reported encouraging long-term
( $>9$ years) results with the use of the Freestyle bioprosthesis for AVR, regardless of the implantation technique (subcoronary or full aortic root replacement). ${ }^{19,22-24}$ In these different 
TABLE 3. Predictors of long-term cardiovascular mortality

\begin{tabular}{|c|c|c|c|c|}
\hline & \multicolumn{2}{|c|}{ Univariable analysis } & \multicolumn{2}{|c|}{ Multivariable analysis } \\
\hline & HR $(95 \%$ CI $)$ & $P$ value & HR $(95 \%$ CI $)$ & $P$ value \\
\hline Age (per y) & $1.06(1.03-1.09)$ & $<.001$ & $1.15(1.08-1.23)$ & $<.001$ \\
\hline Female gender & $0.91(0.64-1.30)$ & .61 & & \\
\hline Body surface area (per unit) & $0.35(0.13-0.94)$ & .04 & - & $>.1$ \\
\hline Preoperative TA mean gradient (per $\mathrm{mm} \mathrm{Hg}$ ) & $0.99(0.97-1.00)$ & .06 & - & $>.1$ \\
\hline Coronary artery disease & $1.57(1.10-2.24)$ & .014 & $1.72(1.0-2.99)$ & .05 \\
\hline Associated surgical procedure & $1.13(0.78-1.65)$ & .52 & & \\
\hline Complete root replacement technique & $0.94(0.35-2.55)$ & .9 & & \\
\hline Previous cardiac surgery & $1.03(0.26-4.2)$ & .96 & & \\
\hline Prosthesis diameter $\leq 21 \mathrm{~mm}$ & $0.98(0.69-1.40)$ & .92 & & \\
\hline Preoperative endocarditis & $2.93(0.72-11.9)$ & .13 & & \\
\hline Baseline LVEF (per \%) & $0.99(0.70-1.0)$ & .11 & & \\
\hline Preoperative creatinine clearance $<60 \mathrm{~mL} / \mathrm{min} / \mathrm{m}^{2}$ & $2.11(1.41-3.15)$ & $<.001$ & $2.0(1.15-3.47)$ & .01 \\
\hline Diabetes mellitus & $1.83(1.21-2.77)$ & .004 & & $>.1$ \\
\hline Preoperative PH & $1.46(0.94-2.25)$ & .09 & & $>.1$ \\
\hline
\end{tabular}

Likelihood ratio test $P<.001$. CI, Confidence interval; $H R$, hazard ratio; $L V E F$, left ventricular ejection fraction; $T A$, transaortic; $P H$, pulmonary hypertension.

series, the 10-year overall survival ranged from $44 \%$ to $47 \%$ and the freedom from SVD ranged from $91 \%$ to $97 \%$. Our present results are in line with these previous observations and confirm the excellent durability of the Freestyle bioprosthesis in the long term, as highlighted by the limited incidence of SVD. Although the overall survival in our cohort was relatively low, this point might be explained by the age of the patients at implantation (mean age, $74.5 \pm 9.6$ years), because the mortality rate in this series was similar to that observed in populations of similar age.${ }^{19}$ We observed that the prominent deterioration mechanism for SVD involved leaflet tear in the majority of cases and only limited calcification. These data support the previous reports of the "wear and tear" phenomenon as the prominent mechanism for SVD in the Freestyle bioprosthesis ${ }^{16}$ and the beneficial role of the alpha-amino oleic acid valve pre-treatment to prevent calcification in vivo.
The comparison between SLB and CSB for survival currently relies on conflicting data, and the putative advantage of the SLB over stented ones remains debated. However, when analyzing the literature, one should bear in mind that these results are inhomogeneous, because they were obtained from studies investigating several SLB types, each with a specific design and specific anti-calcification treatment. These features might account for the differences observed in durability and structural deterioration. ${ }^{25}$ Thus, the Toronto stentless porcine valve (St Jude Medical, Minneapolis, Minn) showed acceptable results on midterm clinical outcome, but late accelerated structural failure after 8 years. $^{3,26}$ We did not observe this phenomenon in the present cohort, and the incidence of SVD and valverelated mortality appeared to be stable in time when compared with midterm results, ${ }^{5}$ supporting the previous reports regarding the excellent durability of the Freestyle

TABLE 4. Predictors of long-term valve-related mortality

\begin{tabular}{|c|c|c|c|c|}
\hline & \multicolumn{2}{|c|}{ Univariable analysis } & \multicolumn{2}{|c|}{ Multivariable analysis } \\
\hline & HR $(95 \%$ CI $)$ & $P$ value & HR $(95 \%$ CI $)$ & $P$ value \\
\hline Age (per y) & $1.07(1.04-1.11)$ & $<.001$ & $1.08(1.05-1.13)$ & $<.001$ \\
\hline Female gender & $1.09(0.73-1.60)$ & .71 & & \\
\hline Body surface area (per unit) & $0.40(0.14-1.20)$ & .10 & - & $>.1$ \\
\hline Preoperative transaortic mean gradient (per $\mathrm{mm} \mathrm{Hg}$ ) & $0.99(0.98-1.01)$ & .31 & & \\
\hline Coronary artery disease & $1.43(0.96-2.11)$ & .08 & - & $>.1$ \\
\hline Associated surgical procedure & $1.28(0.85-1.92)$ & .24 & & \\
\hline Complete root replacement technique & $1.15(0.42-3.15)$ & .78 & & \\
\hline Prosthesis diameter $\leq 21 \mathrm{~mm}$ & $1.10(0.75-1.63)$ & .63 & & \\
\hline Previous cardiac surgery & $1.90(0.60-6.0)$ & .27 & & \\
\hline Preoperative endocarditis & $1.61(0.22-11.6)$ & .64 & & \\
\hline Baseline LVEF (per \%) & $0.99(0.98-1.01)$ & .63 & & \\
\hline Preoperative creatinine clearance $<60 \mathrm{~mL} / \mathrm{min} / \mathrm{m}^{2}$ & $1.32(0.82-2.13)$ & .26 & & \\
\hline Diabetes mellitus & $1.57(0.98-2.51)$ & .06 & $1.62(1.01-2.59)$ & .046 \\
\hline Preoperative $\mathrm{PH}$ & $1.35(0.83-2.20)$ & .23 & & \\
\hline
\end{tabular}

Likelihood ratio test, $P<.001 . C I$, Confidence interval; $H R$, hazard ratio; $L V E F$, left ventricle ejection fraction; $P H$, pulmonary hypertension. 
bioprosthesis. ${ }^{19,22,23}$ Moreover, most of the data currently available on biological prostheses durability have been obtained in observational cohort studies. Thus, a direct comparison between the Freestyle bioprosthesis and the CSB is limited by the potential differences in baseline population characteristics, ${ }^{22,25}$ yet these methodological biases could be overcome by randomized clinical trials. Unfortunately, such data are rare for the Freestyle valve. However, El-Hamamsy and colleagues ${ }^{27}$ observed a better durability and significantly less SVD of the Freestyle device when compared with the homograft for aortic root replacement. ${ }^{27}$ Furthermore, Lehman and colleagues ${ }^{3}$ observed that survival might be improved by using the Freestyle bioprosthesis. Taken together, these different data strongly suggest that the Freestyle bioprosthesis performs similar to CSB and represents a valuable option for AVR in the general population. However, SLB might confer a disadvantage in case of future transaortic valve implantation (TAVI). Because "valve in valve" TAVI emerged as a therapeutic option in elderly patients for redo procedures in degenerated bioprosthesis, ${ }^{28-30}$ concerns have been raised regarding SLB, which may be more prone to coronary coverage during TAVI for prosthetic failure because of to their leaflet height and lack of sinuses or a stent. ${ }^{1}$ Dvir and colleagues ${ }^{29}$ observed that valve-in-valve procedures for SLB degeneration created a higher rate of coronary ostial obstruction than the stented valves.

The evolution of the younger $(<65$ years $)$ and older ( $>80$ years) patients in this cohort also deserves special consideration. The use of conventional biological prostheses is usually avoided in younger patients because of the increased risk of device degradation leading to increased rates of $\mathrm{SVD}^{1}$ (as high as $26 \%, 15$ years after $\mathrm{AVR}^{31}$ ). In the present study, we observed an $89 \%$ of freedom from SVD at 10 years, confirming our previous midterm analysis $^{5}$ and other long-term outcome results. ${ }^{32}$ Thus, the putative advantage of the Freestyle bioprosthesis over CSB and in terms of durability for this special group of patients seems justified. The Freestyle bioprosthesis may represent an alternative to a homograft in young patients ${ }^{27}$ and could be considered when a bioprosthesis is required because the risk for eventual reoperation is known to be similar to that for primary isolated AVR. ${ }^{33}$ In this young (and often very active) population, a full root replacement might be an attractive option when the annulus size is less than $23 \mathrm{~mm}$, to ensure optimal hemodynamics in these physically demanding patients. ${ }^{34}$ Finally, we also observed acceptable long-term survival in a large cohort of subjects aged more than 80 years (in consideration of the life expectancy of these patients in the general population). Although the implantation of SLB remains highly debated in this subpopulation considering the higher technical complexity and longer cardiopulmonary bypass time, these results are encouraging and in line with data previously reported by Ennker and colleagues. ${ }^{35}$ Thus, the Freestyle bioprosthesis may be a valuable option for AVR in octogenarians. ${ }^{5}$

\section{Study Limitations}

The present study is an observational assessment of outcomes. Patients were not randomly assigned to various therapies, and comparison between inherently dissimilar groups is problematic. Clinical follow-up was available through 12 years, but hemodynamic outcomes were not measured during this period in all patients, which does not allow us to draw any conclusion regarding this aspect, especially about long-term evolution and left ventricular remodeling.

\section{CONCLUSIONS}

The use of the Freestyle bioprosthesis for AVR resulted in good long-term cardiovascular survival at any age in this all-comers 500-patient cohort. These data suggest that this bioprosthesis could be considered as a valuable option for AVR, particularly for young patients aged more than 30 years who refuse the use of mechanical valves.

The authors thank Emmanuelle Pineau, MD, for data collection and database management and Marie Cécile Perier, MSc, for additional statistics analysis.

\section{References}

1. Svensson LG, Adams DH, Bonow RO, Kouchoukos NT, Miller DC, O'Gara PT, et al. Aortic valve and ascending aorta guidelines for management and quality measures. Ann Thorac Surg. 2013;95(6 Suppl):S1-66.

2. Gulbins H, Reichenspurner H. Which patients benefit from stentless aortic valve replacement? Ann Thorac Surg. 2009;88:2061-8.

3. Lehmann S, Walther T, Kempfert J, Leontjev S, Rastan A, Falk V, et al. Stentless versus conventional xenograft aortic valve replacement: midterm results of a prospectively randomized trial. Ann Thorac Surg. 2007;84:467-72.

4. Kunadian B, Vijayalakshmi K, Thornley AR, de Belder MA, Hunter S, Kendall S, et al. Meta-analysis of valve hemodynamics and left ventricular mass regression for stentless versus stented aortic valves. Ann Thorac Surg. 2007;84:73-8.

5. Deleuze PH, Fromes Y, Khoury W, Maribas P, Lemaire S, Bical OM. Eight-year results of Freestyle stentless bioprosthesis in the aortic position: a single-center study of 500 patients. J Heart Valve Dis. 2006;15:247-52.

6. Westaby S, Amarasena N, Ormerod O, Amarasena GA, Pillai R. Aortic valve replacement with the freestyle stentless xenograft. Ann Thorac Surg. 1995; 60(2 Suppl):S422-7.

7. Kon ND, Cordell AR, Adair SM, Dobbins JE, Kitzman DW. Aortic root replacement with the freestyle stentless porcine aortic root bioprosthesis. Ann Thorac Surg. 1999;67:1609-15.

8. Baumgartner H, Hung J, Bermejo J, Chambers JB, Evangelista A, Griffin BP, et al. Echocardiographic assessment of valve stenosis: EAE/ASE recommendations for clinical practice. J Am Soc Echocardiogr. 2009;22:1-23.

9. Fuster V, Ryden LE, Asinger RW, Cannom DS, Crijns HJ, Frye RL, et al. ACC/ AHA/ESC guidelines for the management of patients with atrial fibrillation. A report of the American College of Cardiology/American Heart Association Task Force on Practice Guidelines and the European Society of Cardiology Committee for Practice Guidelines and Policy Conferences (Committee to develop guidelines for the management of patients with atrial fibrillation) developed in collaboration with the North American Society of Pacing and Electrophysiology. Eur Heart J. 2001;22:1852-923.

10. Akins CW, Miller DC, Turina MI, Kouchoukos NT, Blackstone EH, Grunkemeier GL, et al. Guidelines for reporting mortality and morbidity after cardiac valve interventions. J Thorac Cardiovasc Surg. 2008;135:732-8. 
11. Grunkemeier GL, Eric Jamieson WR, Miller DC, Starr A. Actuarial versus actual risk of porcine structural valve deterioration. J Thorac Cardiovasc Surg. 1994; 108:709-18.

12. Cohen G, Zagorski B, Christakis GT, Joyner CD, Vincent J, Sever J, et al. Are stentless valves hemodynamically superior to stented valves? Long-term followup of a randomized trial comparing Carpentier-Edwards pericardial valve with the Toronto Stentless Porcine Valve. J Thorac Cardiovasc Surg. 2010;139:848-59.

13. Matsue H, Sawa Y, Matsumiya G, Matsuda H, Hamada S. Mid-term results of freestyle aortic stentless bioprosthetic valve: clinical impact of quantitative analysis of in-vivo three-dimensional flow velocity profile by magnetic resonance imaging. J Heart Valve Dis. 2005;14:630-6.

14. Fries R, Wendler O, Schieffer H, Schafers HJ. Comparative rest and exercise hemodynamics of 23-mm stentless versus 23-mm stented aortic bioprostheses. Ann Thorac Surg. 2000;69:817-22.

15. Mohammadi S, Baillot R, Voisine P, Mathieu P, Dagenais F. Structural deterioration of the Freestyle aortic valve: mode of presentation and mechanisms. J Thorac Cardiovasc Surg. 2006;132:401-6.

16. Mohammadi S, Tchana-Sato V, Kalavrouziotis D, Voisine P, Doyle D, Baillot R, et al. Long-term clinical and echocardiographic follow-up of the Freestyle stentless aortic bioprosthesis. Circulation. 2012;126(11 Suppl 1):S198-204.

17. Anselmi A, Flécher E, Ruggieri VG, Harmouche M, Langanay T, Corbineau H, et al. Long-term results of the Medtronic Mosaic porcine bioprosthesis in the aortic position. J Thorac Cardiovasc Surg. 2013 Aug 26 [Epub ahead of print].

18. Blais C, Dumesnil JG, Baillot R, Simard S, Doyle D, Pibarot P. Impact of valve prosthesis-patient mismatch on short-term mortality after aortic valve replacement. Circulation. 2003;108:983-8.

19. Ennker JA, Ennker IC, Albert AA, Rosendahl UP, Bauer S, Florath I. The Freestyle stentless bioprosthesis in more than 1000 patients: a single-center experience over 10 years. J Card Surg. 2009;24:41-8.

20. Bridges CR, O'Brien SM, Cleveland JC, Savage EB, Gammie JS, Edwards FH, et al. Association between indices of prosthesis internal orifice size and operative mortality after isolated aortic valve replacement. J Thorac Cardiovasc Surg. 2007; 133:1012-21.

21. Jin XY, Pepper JR. Do stentless valves make a difference? Eur J Cardiothorac Surg. 2002;22:95-100.

22. Bach DS, Kon ND, Dumesnil JG, Sintek CF, Doty DB. Ten-year outcome after aortic valve replacement with the freestyle stentless bioprosthesis. Ann Thorac Surg. 2005;80:480-6.

23. Kappetein AP, Puvimanasinghe JP, Takkenberg JJ, Steyerberg EW, Bogers AJ. Predicted patient outcome after aortic valve replacement with Medtronic Stentless Freestyle bioprostheses. J Heart Valve Dis. 2007;16:423-8.
24. Ennker JA, Albert AA, Rosendahl UP, Ennker IC, Dalladaku F, Florath I Ten-year experience with stentless aortic valves: full-root versus subcoronary implantation. Ann Thorac Surg. 2008;85:445-52.

25. Funder JA. Current status on stentless aortic bioprosthesis: a clinical and experimental perspective. Eur J Cardiothorac Surg. 2012;41: 790-9.

26. Desai ND, Merin O, Cohen GN, Herman J, Mobilos S, Sever JY, et al. Long-term results of aortic valve replacement with the St. Jude Toronto stentless porcine valve. Ann Thorac Surg. 2004;78:2076-83.

27. El-Hamamsy I, Clark L, Stevens LM, Sarang Z, Melina G, Takkenberg JJM, et al. Late outcomes following Freestyle versus homograft aortic root replacement: results from a prospective randomized trial. J Am Coll Cardiol. 2010;55: 368-76.

28. Bapat V, Attia R, Redwood S, Hancock J, Wilson K, Young C, et al. Use of transcatheter heart valves for a valve-in-valve implantation in patients with degenerated aortic bioprosthesis: technical considerations and results. J Thorac Cardiovasc Surg. 2012;144:1372-80.

29. Dvir D, Webb J, Brecker S, Bleiziffer S, Hildick-Smith D, Colombo A, et al Transcatheter aortic valve replacement for degenerative bioprosthetic surgical valves: results from the Global Valve-in-Valve Registry. Circulation. 2012; 126:2335-44.

30. Ihlberg L, Nissen H, Nielsen N-E, Rück A, Busund R, Klaarborg K-E, et al. Early clinical outcome of aortic transcatheter valve-in-valve implantation in the Nordic countries. J Thorac Cardiovasc Surg. 2013;146:1047-54.

31. Hammermeister K, Sethi GK, Henderson WG, Grover FL, Oprian C, Rahimtoola SH. Outcomes 15 years after valve replacement with a mechanical versus a bioprosthetic valve: final report of the Veterans Affairs randomized trial. J Am Coll Cardiol. 2000;36:1152-8.

32. Bach DS, Metras J, Doty JR, Yun KL, Dumesnil JG, Kon ND. Freedom from structural valve deterioration among patients aged $<$ or $=60$ years undergoing Freestyle stentless aortic valve replacement. J Heart Valve Dis. 2007;16: 649-55.

33. Potter DD, Sundt TM 3rd, Zehr KJ, Dearani JA, Daly RC, Mullany CJ, et al. Operative risk of reoperative aortic valve replacement. J Thorac Cardiovasc Surg. 2005;129:94-103.

34. Bach DS, Cartier PC, Kon ND, Johnson KG, Deeb GM, Doty DB, et al. Impact of implant technique following freestyle stentless aortic valve replacement. Ann Thorac Surg. 2002;74:1107-13.

35. Ennker J, Dalladaku F, Rosendahl U, Ennker IC, Mauser M, Florath I. The stentless freestyle bioprosthesis: impact of age over 80 years on quality of life, perioperative, and mid-term outcome. J Card Surg. 2006;21:379-85.

\section{EDITORIAL COMMENTARY}

\section{Do stentless valves make a difference?}

\section{John Pepper, MD}

See related article on pages 1903-11.

From the Department of Surgery, Royal Brompton Hospital, London, United Kingdom.

Disclosures: Author has nothing to disclose with regard to commercial support.

Received for publication Sept 11, 2014; accepted for publication Sept 12, 2014

Address for reprints: John Pepper, MD, NHR Biological Research Unit,

Royal Brompton Hospital, Sydney St, London SW3 6NP, United Kingdom

(E-mail: j.pepper@rbht.nhs.uk).

J Thorac Cardiovasc Surg 2014;148:1911-2

$0022-5223 / \$ 36.00$

Copyright (c) 2014 by The American Association for Thoracic Surgery

http://dx.doi.org/10.1016/j.jtcvs.2014.09.019
In the early 1960s, Ross and Barratt-Boyes separately introduced the aortic homograft into clinical practice. In 1965, Binet and colleagues ${ }^{1}$ introduced a stentless porcine bioprosthesis, but this was not pursued because of difficulties with implantation at a time when myocardial protection was in its infancy. Stented bioprostheses were therefore developed because their placement required a much simpler technique and resulted in a reproducible performance. Nevertheless, the transvalvular gradients and limited durability became major concerns. The original free-sewn homograft circumvents most of these problems, but its limited availability prevents its widespread use. This 